This item was submitted to Loughborough's Research Repository by the author.

Items in Figshare are protected by copyright, with all rights reserved, unless otherwise indicated.

\title{
Control of Mose2 formation in hydrazine-free solution-processed CIS/CIGS thin film solar cells
}

PLEASE CITE THE PUBLISHED VERSION

https://doi.org/10.1109/PVSC.2017.8366174

PUBLISHER

(C) IEEE

VERSION

AM (Accepted Manuscript)

LICENCE

CC BY-NC-ND 4.0

\section{REPOSITORY RECORD}

Ulicna, Sona, Panagiota Arnou, Alexander Eeles, Mustafa Togay, Lewis D. Wright, Ali Abbas, Andrei V. Malkov, Michael Walls, and Jake W. Bowers. 2019. "Control of Mose2 Formation in Hydrazine-free Solutionprocessed CIS/CIGS Thin Film Solar Cells”. figshare. https://hdl.handle.net/2134/25996. 


\title{
Control of $\mathrm{MoSe}_{2}$ formation in hydrazine-free solution-processed CIS/CIGS thin film solar cells
}

\author{
Soňa Uličná ${ }^{1 *}$, Panagiota Arnou ${ }^{1}$, Alexander Eeles ${ }^{1}$, Mustafa Togay ${ }^{1}$, Lewis D. Wright ${ }^{1}$, Ali Abbas ${ }^{1}$, Andrei \\ V. Malkov ${ }^{2}$, John M. Walls ${ }^{1}$ and Jake W. Bowers ${ }^{1}$ \\ ${ }^{1}$ CREST, Wolfson School of Mechanical, Electrical and Manufacturing Engineering, ${ }^{2}$ Department of \\ Chemistry, Loughborough University, Loughborough, Leicestershire, LE11 3TU, UK
}

\begin{abstract}
This study investigated an approach to control the $\mathrm{MoSe}_{2}$ layer formation at the Mo/CIGS interface of hydrazinefree solution-processed CIGS solar cells. The $\mathrm{MoSe}_{2}$ layer thickness reduction was achieved by deposition of a $\mathrm{MoN}_{\mathrm{x}}$ back contact barrier layer, which effectively acts as a diffusion barrier against selenium (Se). The resulting $\mathrm{Mo} / \mathrm{MoN}_{\mathrm{x}} / \mathrm{Mo}$ multilayer was applied in a CIGS device as the back contact. The electrical performance of this device was compared to our baseline approach with bare Mo as the back contact. The $\mathrm{MoSe}_{2}$ layer formed after selenization was dramatically reduced when the barrier layer was present and the corresponding device exhibited a power conversion efficiency (PCE) of $8.2 \%$. More importantly, the application of the barrier layer as an intermediate layer within the Mo back contact allows for longer, or even multiple selenization steps. A longer or a multiple selenization was shown to improve the absorber grain growth and consequently result in higher PCEs.

Index Terms - CIGS, diffusion barrier, $\mathrm{MoN}_{\mathrm{x}}, \mathrm{MoSe}_{2}$, selenization, solution-process.
\end{abstract}

\section{INTRODUCTION}

$\mathrm{Cu}(\mathrm{In}, \mathrm{Ga}) \mathrm{Se}_{2}$ is one of the best performing thin-film photovoltaic technologies [1]. High efficiencies are however achieved using expensive and sophisticated vacuum-based equipment. To reduce the production costs, non-vacuum solution-based deposition approaches for the absorber layer are of increased popularity. These techniques promise many potential advantages. As well as the lower capital cost, solution approaches offer process simplicity, straightforward compositional control, large area uniformity and the possibility for flexible substrate application. So far, the best performing true solution-based CIGS solar cell with a PCE of $15.2 \%$ was developed using hydrazine as the solvent [2]. This fabrication method has overcome some of the limitations of non-vacuum techniques, such as phase impurity and incomplete grain growth. However the large scale implementation of this method is difficult due to hydrazine being an extremely hazardous solvent.

A hydrazine-free solvent combination consisting of 1,2ethanedithiol/1,2-ethylenediamine (eth/en) in a 1:10 volumetric ratio was found to effectively dissolve metal chalcogenides [3]. In our previous work, this diamine/dithiol solvent mixture was used as a safer alternative to hydrazine to prepare CIGS precursor solutions by dissolving copper and indium sulfides, as well as elemental gallium and selenium. The solution was spray-coated in air onto molybdenum (Mo) coated substrates followed by post-deposition selenization. This method resulted in PCEs up to $8 \%$ for CIS and 9.8\% for CIGS solar cells [4]. A similar molecular precursor route using amine-thiol mixture was developed to fabricate CIGSe from elemental Cu, In, Ga and Se with a reported PCE of 9.5\% [5] and from a combination of metal salts and chalcogenides reporting PCE of 12.2\% [6]. Although these methods are very promising for a scalable industrial application, there is still a large room for further improvement in terms of device performance.

Currently, one of the limiting factors of these devices is the excessive $\mathrm{MoSe}_{2}$ formation during the high temperature selenization step. A thin $\mathrm{MoSe}_{2}$ layer is beneficial as it forms an ohmic contact at the Mo/CIGS interface. However, excessive formation of $\mathrm{MoSe}_{2}$ can have detrimental effects on the device performance, by decreasing the fill factor (FF) and causing adhesion problems [7]. Some of the factors that can affect the $\mathrm{MoSe}_{2}$ formation are the sputtering conditions for Mo, residual stress in the film, selenization conditions or presence of sodium $(\mathrm{Na})$ [8]. Selenium diffusion barriers have been previously reported to hinder the excessive transformation of Mo into $\mathrm{MoSe}_{2}$. These include TiN, molybdenum oxide $\left(\mathrm{MoO}_{\mathrm{x}}\right)$ and molybdenum nitride $\left(\mathrm{MoN}_{\mathrm{x}}\right)$ [9]-[11].

The purpose of this work is to investigate the impact of the $\mathrm{MoN}_{\mathrm{x}}$ diffusion barrier and the selenization configuration on the $\mathrm{MoSe}_{2}$ layer formation. Subsequent CIGS devices were fabricated using these substrates and were compared with a baseline sample without the barrier layer.

\section{EXPERIMENTAL DETAILS}

\section{A. Molybdenum deposition}

A $\mathrm{MoN}_{\mathrm{x}}$ thin film of $\sim 30 \mathrm{~nm}$ thickness was deposited onto a $600 \mathrm{~nm}$ thick Mo coated soda-lime glass (SLG) substrate. The Mo layer had a bilayer structure, as this is optimized for high quality CIGS solar cells [12]. The $\mathrm{MoN}_{\mathrm{x}}$ barrier layer was deposited using DC magnetron sputtering at a base pressure lower than $3 \times 10^{-6}$ Torr. A mixture of $\mathrm{Ar} / \mathrm{N}_{2}$ sputtering gases (10/5 sccm) was introduced into the sputtering chamber, 
resulting in a working pressure of 2.4 mTorr. The deposition was carried out using a power density of $4 \mathrm{~W} / \mathrm{cm}^{2}$. Finally a $\sim 50 \mathrm{~nm}$ thick Mo layer was deposited on top of the $\mathrm{MoN}_{\mathrm{x}}$ layer, using $2 \mathrm{sccm}$ of $\mathrm{Ar}$ and a sputter power and pressure of $4 \mathrm{~W} / \mathrm{cm}^{2}$ and $1.2 \mathrm{mTorr}$ respectively. The sheet resistance of the final $\mathrm{Mo} / \mathrm{MoN}_{\mathrm{x}} / \mathrm{Mo}$ multilayer remained unchanged compared to the Mo single layer due to the $\mathrm{MoN}_{\mathrm{x}}$ film being relatively thin.

\section{B. Deposition of CIGS absorber films and fabrication of solar cells}

$\mathrm{Cu}(\mathrm{In}, \mathrm{Ga})(\mathrm{S}, \mathrm{Se})_{2}$ films were prepared in two steps. First, the precursor solution was deposited onto the modified Mo coated substrates. Secondly, the as-deposited film was thermally annealed in Se atmosphere to recrystallize the absorber layer.

Metal chalcogenides (copper and indium sulfides, elemental gallium in presence of excess selenium) were dissolved in the eth/en solvent mixture as described in our previous work [4]. The $\mathrm{Cu}_{0.9} \mathrm{In}_{0.7} \mathrm{Ga}_{0.3} \mathrm{Se}_{2}$ precursor solution was diluted with ethyl acetate $(2: 1 \mathrm{v} / \mathrm{v})$, filtered $(0.45 \mu \mathrm{m}$ PTFE) and subsequently sprayed in layers onto the Mo coated substrates placed on a preheated hot plate. Each sprayed layer was immediately dried to evaporate the excess solvent. The final film consisted of 6 sprayed layers in total to obtain a film thickness of 2-3 $\mu \mathrm{m}$. The precursor film was then selenized in a tube furnace. The sample is placed together with Se pellets in a partially closed graphite box heated at $540^{\circ} \mathrm{C}$ for $50-90$ minutes, including the ramping $\left(\sim 40^{\circ} \mathrm{C} / \mathrm{min}\right)$, at a starting pressure of 450 Torr. The single selenized samples on bare Mo are denoted as 'S-50' and 'S-90', with 50 and 90 indicating the annealing time. The single selenized samples that contain $\mathrm{MoN}_{\mathrm{x}}$ barrier layer are denoted as 'SB-50' and 'SB-70'. In a separate approach, a thinner absorber (3 sprayed layers) was selenized using the same conditions. The spraying and selenization procedure was then repeated in the same way. The final device consists of 6 sprayed layers and was selenized for 100 minutes in total. The double selenized sample is denoted as 'D-50-50'.

CIGS devices were completed by chemical bath deposition of CdS buffer layer and sputtering of intrinsic $\mathrm{ZnO}$ and $\mathrm{Al}$ doped ZnO (AZO). A top contact silver grid was evaporated. Mechanical scribing was performed to delimit cells of a total area of $\sim 0.25 \mathrm{~cm}^{2}$.

\section{Characterization}

Transmission Electron Microscopy (TEM) was carried out using FEI Tecnai F20 (S)TEM equipped with an Oxford Instruments X-Max 80 silicon drift detector (SDD) Energy Dispersive X-ray detector (EDX). The TEM samples were prepared by Focused Ion Beam (FIB) milling using a dual beam FEI Nova 600 Nanolab. The absorber microstructure was observed using a JEOL JSM-7800F Field Emission Scanning Electron Microscope (FE-SEM) equipped with EDX. X-ray diffraction (XRD) was performed using a Bruker D2 Phaser X-ray diffractometer equipped with a Lynxeye ${ }^{\mathrm{TM}}$ detector and $\mathrm{Cu}-\mathrm{K} \alpha \mathrm{X}$-ray source. The current density/voltage (JV) characteristics of the individual cells were measured using AM1.5G simulated sunlight from a dual source solar simulator (Wacom, Japan) under $100 \mathrm{mWcm}^{-2}$, using a calibrated Si reference cell. Prior to the JV measurements, the cell area was measured using a digital microscope. The external quantum efficiency (EQE) spectra were acquired with chopped light using a Bentham PVE300 system. The measurements were performed at $0 \mathrm{~V}$ bias with a spectral resolution of $5 \mathrm{~nm}$. Temperature-dependent current density/voltage (JVT) measurements were performed using a Lakeshore 335 temperature controller by heating or cooling through a Janis CCS150 closed cycle helium cryostat. Capacitance-Voltage (CV) measurements were performed using a Keysight E4990A impedance analyzer and four-point probe at room temperature.

\section{RESULTS}

The biggest obstacles against achieving higher PCEs for the solution-processed CIGS solar cells are the non-optimized back contact and a poorly recrystallized absorber. It is expected that a reduction in the $\mathrm{MoSe}_{2}$ layer thickness can lead to lower series resistance $\left(\mathrm{R}_{\mathrm{S}}\right)$ and therefore increased $\mathrm{FF}$.

The TEM cross-section of the $\mathrm{Mo} / \mathrm{MoN}_{\mathrm{x}} / \mathrm{Mo}$ multilayer after 50 minutes-long selenization is shown in Fig. 1. EDX elemental maps show that Se diffusion is effectively blocked from migrating towards the substrate and converting the entire Mo layer into $\mathrm{MoSe}_{2}$. The top $50 \mathrm{~nm}$ thick Mo was all converted into a thick $\mathrm{MoSe}_{2}$ with a thickness of $>200 \mathrm{~nm}$. This confirms the role of the $\mathrm{MoN}_{\mathrm{x}}$ as an effective diffusion barrier against Se migration.

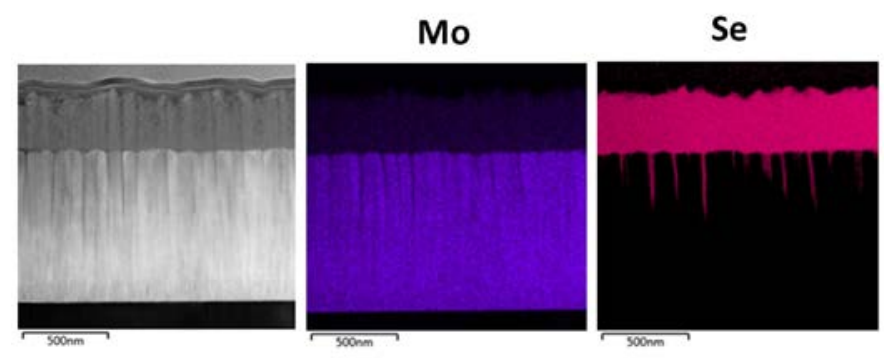

Fig. 1. TEM cross-section and EDX elemental maps of the $\mathrm{Mo} / \mathrm{MoN}_{\mathrm{X}} / \mathrm{Mo}$ multilayer after selenization.

A more aggressive selenization is often required in order to fully recrystallize the absorber. However, this may cause delamination due to formation of a thick $\mathrm{MoSe}_{2}$ layer. Therefore, a compromise needed to be made in the choice of the selenization conditions, resulting in incompletely crystallized absorbers. A bilayer is typically formed after selenization of solution-processed CIGS, consisted of an uncrystallized part at the bottom and larger grains on the top. This is suspected to be a limiting factor towards achieving higher efficiencies [13]. Longer dwell times and higher selenium partial pressures during selenization are expected to 
improve the crystal quality of the absorber. However, the process window for the selenization step is limited by the excessively thick $\mathrm{MoSe}_{2}$ layer that may be formed, causing delamination issues.

The $\mathrm{MoSe}_{2}$ layer was effectively controlled by introducing the $\mathrm{MoN}_{\mathrm{x}}$ barrier layer. The XRD patterns in Fig. 2 show distinct peaks corresponding to the chalcopyrite structure of CIGS (JCPDS 40-1488 of $\mathrm{CuIn}_{0.5} \mathrm{Ga}_{0.5} \mathrm{Se}_{2}$ ).

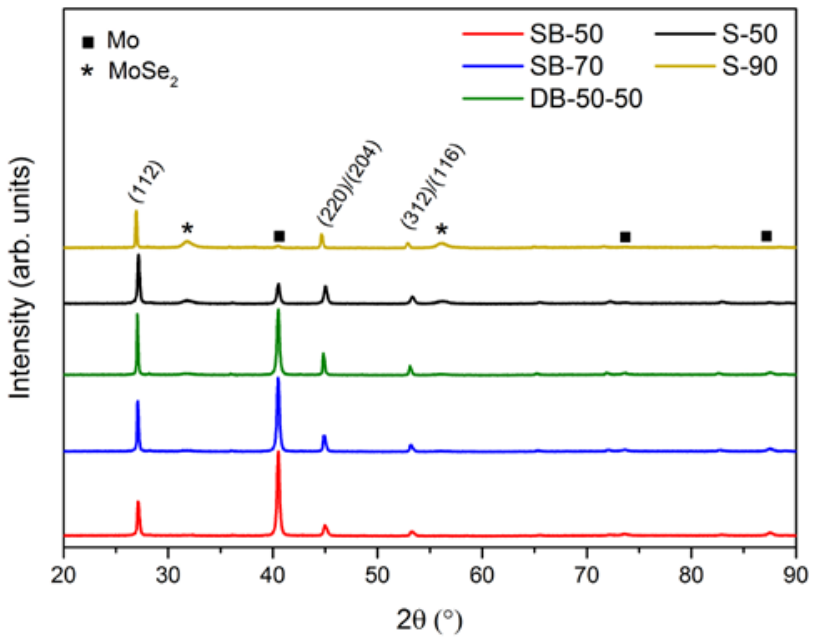

Fig. 2. XRD patterns of the CIGS devices showing the increase of $\mathrm{Mo} / \mathrm{MoSe}_{2}$ ratio with introducing the $\mathrm{MoN}_{\mathrm{x}}$ barrier layer.

The intensity of the $\mathrm{MoSe}_{2}$ (100) peak at $2 \theta \sim 32^{\circ}$ is substantially decreased when the barrier layer is present. This peak is more pronounced for the barrier-free samples. Table I summarizes the Mo (110)/MoSe 2 (100) peak intensity ratio extracted from the XRD data. The ratio is substantially higher when the barrier layer is present, 41.92 ('SB-50') compared to 4.35 for ' $\mathrm{S}-50$ '. However it decreases with longer selenization durations, from 41.92 to 24.91 for the 'D-50-50' sample. It was shown in Fig. 1 that the barrier layer allows locally some selenium to go through the barrier layer and form $\mathrm{MoSe}_{2}$. It is likely that Se diffuses through the barrier to a bigger extend for the longer selenized samples.

TABLE I

FWHM AND INTENSITY RATIOS OF THE XRD PEAKS

\begin{tabular}{|c|c|c|c|c|}
\hline & \multicolumn{3}{|c|}{$\mathrm{FWHM}\left({ }^{\circ}\right)$} & Intensity \\
\hline & $\begin{array}{l}\text { CIGS } \\
(112)\end{array}$ & $\begin{array}{c}\text { Mo } \\
(110)\end{array}$ & $\begin{array}{l}\mathrm{MoSe}_{2} \\
(100)\end{array}$ & $\begin{array}{c}\text { Mo (110) / } \\
\operatorname{MoSe}_{2}(100)\end{array}$ \\
\hline SB-50 & 0.254 & 0.317 & NA & 41.92 \\
\hline SB-70 & 0.193 & 0.316 & NA & 30.07 \\
\hline DB-50-50 & 0.161 & 0.317 & NA & 24.91 \\
\hline S-50 & 0.249 & 0.333 & NA & 4.35 \\
\hline S-90 & 0.161 & NA & 1.09 & 0.42 \\
\hline
\end{tabular}

The extracted full width at half maximum (FWHM) of the dominant (112) CIGS peak gives an indication of the crystal growth during selenization. The crystal growth does not seem to be significantly affected by the presence of the barrier layer with a FWHM value of $\sim 0.25^{\circ}$ for both 'SB-50' and 'S-50' samples. On the other hand the FWHM decreases to $0.193^{\circ}$ with longer selenization times and even to $0.161^{\circ}$ for the double selenized absorber.

The SEM images of the absorber surface and cross-sections displayed in Fig. 3 are in agreement with the XRD observations. First, the reduced $\mathrm{MoSe}_{2}$ thickness can be clearly seen on the cross-section of the sample with the barrier layer. The sample can withstand even longer or multiple selenizations, without formation of cracks or delamination at the back contact. On the contrary, delamination is evident for the barrier-free sample selenized for longer times ' $\mathrm{S}-90$ '. Secondly, the bilayer structure of large/small crystals is seen in all single (S) selenized absorbers. The grain size in the top crystallized layer increases with longer selenization time ('SB70'). Larger grains are present in the bulk rather than on the surface after the double selenization ('DB-50-50').

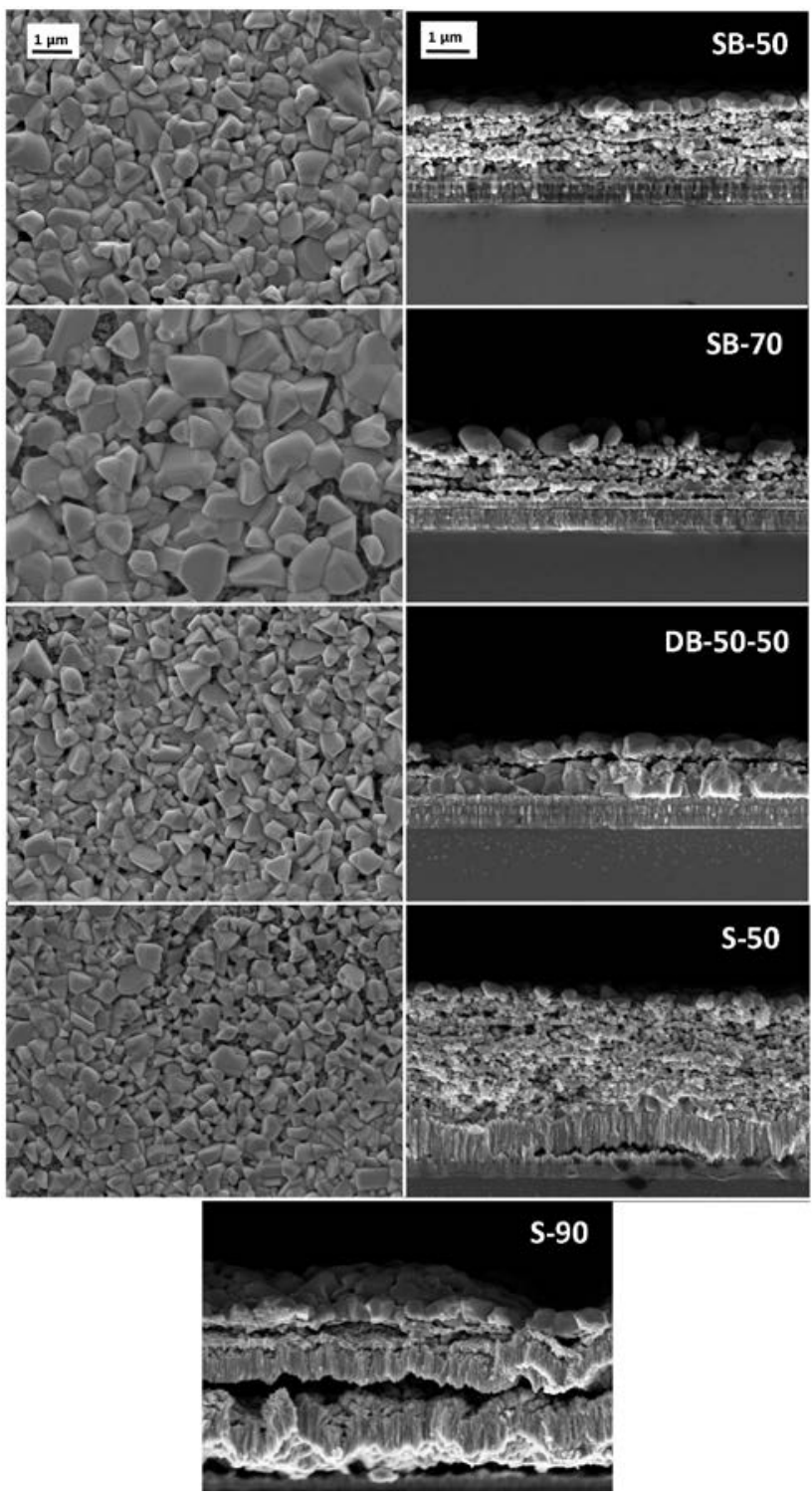

Fig. 3. SEM surface and cross-section images of the samples. 
The light and dark JV characteristics of the champion cell for each sample are displayed in Fig. 4. The key performance indicators corresponding to each of the JV curves are summarized in Table II. The best performing cell is the 'SB70' with a PCE of $9.0 \%$. This confirms that the presence of the $\mathrm{MoN}_{\mathrm{x}}$ barrier layer does not detriment the device properties. This device has the highest open circuit voltage $\left(\mathrm{V}_{\mathrm{OC}}\right)(622 \mathrm{mV})$ and the highest short circuit current $\left(\mathrm{J}_{\mathrm{SC}}\right)$ $\left(24.3 \mathrm{~mA} / \mathrm{cm}^{2}\right)$ among the compared samples. Surprisingly, the 'DB-50-50' device has a lower performance considering the improved crystal growth seen by SEM (Fig. 3). However, this device has the highest FF, exceeding $64 \%$. The increase in FF is most likely associated with the improved crystallization in the bulk of the absorber causing lower $R_{S}$ losses. The low performance of the 'S-90' cell can be attributed mainly to the poor quality of the back contact. A $1.5 \%$ increase in the PCE was obtained for the 'SB-50' sample in comparison to the 'S50', showing the beneficial effect of the barrier layer. The unintentional thickness variation between the two samples can also affect the device performance.

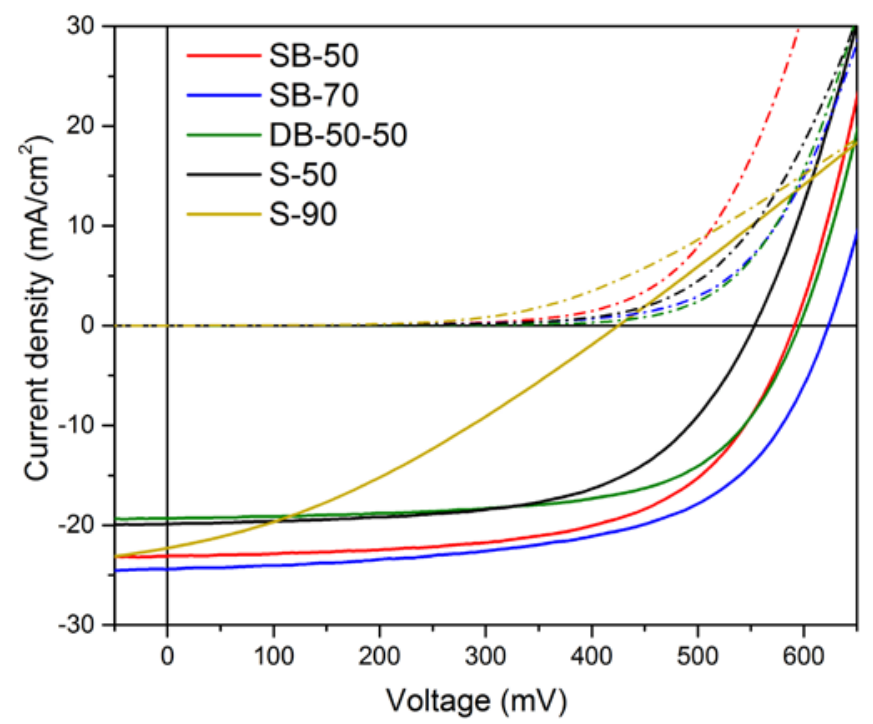

Fig. 4. Light and dark JV curves of representative devices.

TABLE II

Key Performance Indicators Of EACH Of The Displayed JV CURVES IN FIG. 4

\begin{tabular}{|c|cccc|}
\hline & $\begin{array}{c}\text { Efficiency } \\
(\%)\end{array}$ & $\begin{array}{c}\text { FF } \\
(\%)\end{array}$ & $\begin{array}{c}\mathrm{V}_{\mathrm{OC}} \\
(\mathrm{mV})\end{array}$ & $\begin{array}{c}\mathrm{J}_{\mathrm{SC}} \\
\left(\mathrm{mA} / \mathrm{cm}^{2}\right)\end{array}$ \\
\hline SB-50 & 8.2 & 60 & 590 & 23.0 \\
SB-70 & 9.0 & 59 & 622 & 24.3 \\
DB-50-50 & 7.3 & 64 & 595 & 19.2 \\
S-50 & 6.5 & 59 & 553 & 19.8 \\
S-90 & 3.1 & 32 & 425 & 22.2 \\
\hline
\end{tabular}

To further investigate the effect of the barrier layer on the device properties, EQE, EDX, CV and JVT characterization were performed. The presence of the barrier layer can also affect the doping density of the device, by limiting $\mathrm{Na}$ diffusion from the SLG substrate. There is also a possibility that the barrier can affect the absorber composition, as it may prevent $\mathrm{Cu}$ migration into the $\mathrm{MoSe}_{2}$. The $\mathrm{Cu}$ out-diffusion into the back contact may be possible in barrier-free CIGS solar cells [14]. Fig. 5 shows the extracted doping profiles from the CV measurements at $300 \mathrm{~K}$.

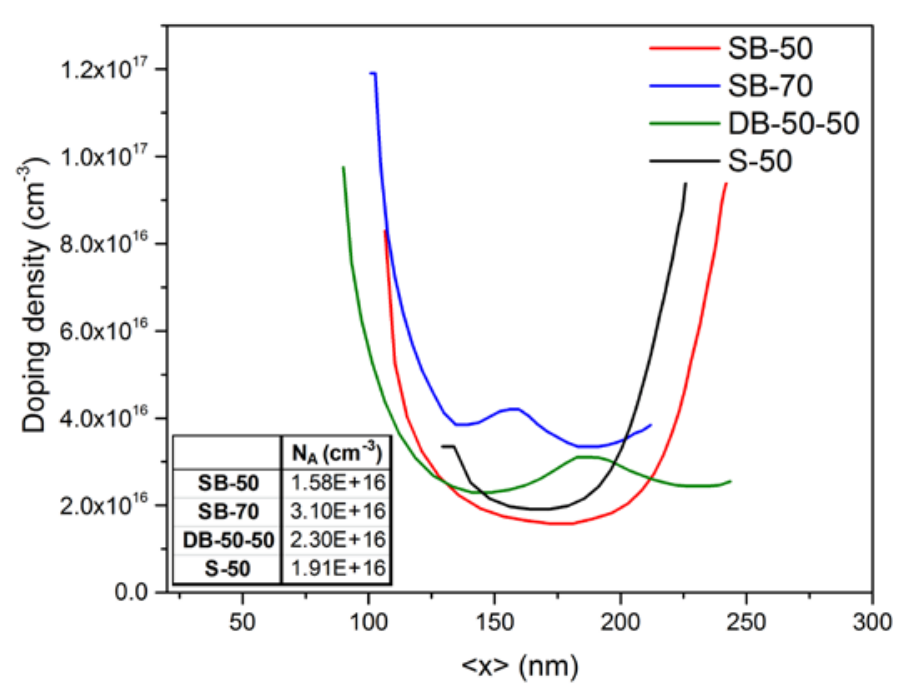

Fig. 5. Room temperature doping profiles for the devices with and without the $\mathrm{MoN}_{\mathrm{x}}$ barrier layer.

Both samples selenized for 50 min display U-shape profiles. The doping densities were estimated from the minima of these curves. The net doping density is the lowest for the 'SB-50' device. This could be caused by reduced sodium diffusion from SLG due to the presence of barrier, but these changes are too small to be conclusive on the Na-blocking effect of the barrier layer. Moreover, the double and longer selenized devices on the barrier layer show higher doping densities than the device on bare Mo. This indicates that a sufficient amount of Na could be diffused through discontinuities in the $\mathrm{MoN}_{\mathrm{x}}$, as seen in Fig. 1. Alternatively, higher $\mathrm{Cu}$ amounts could be present in the absorber, either introduced unintentionally or due to $\mathrm{MoN}_{\mathrm{x}}$ barrier layer that would block the $\mathrm{Cu}$ migration into the $\mathrm{MoSe}_{2}$ [14]. A further analysis is needed in order to quantify the $\mathrm{Na}$ and $\mathrm{Cu}$ contents in the samples.

The doping profiles of these two samples have an unusual shape presenting a local maximum and two minimums. It seems reasonable to assume that the unusual doping density profile is connected to the double layer structure of the devices. It could represent a genuine doping profile or an artifact caused roughness and incomplete coverage of the large crystal layer. From the SEM cross section (Fig. 3), the devices which display this double dip characteristic have a much larger top crystal region ( 500nm) compared to the devices which do not $(\sim 200 \mathrm{~nm})$. We interpret this as showing the large crystal region is fully depleted in the devices with short selenizations, whereas for the long and double selenizations the depletion width crosses the interface between the large and small layers 
during the voltage sweep. This is not consistent with the measured profile depth $\langle\mathrm{x}\rangle$ however this measure is strongly affected by deep defects and interface states, which could have artificially lowered its value [15].

The EDX data summarized in Table III show that the $\mathrm{Ga} / \mathrm{In}+\mathrm{Ga}$ (GGI) ratio agrees well with the targeted values. No significant $\mathrm{Ga}$ loss is observed during longer selenizations. The deviation of $\mathrm{Cu}$ and Se contents might be related to unintentional deposition variations rather than the effect of the barrier or the selenization duration.

\section{TABLE III}

ELEMENTAL COMPOSITION Of EACH FILM COMPARED TO THE TARGETED CIGS COMPOSITION

\begin{tabular}{|c|ccccc|}
\hline & Targeted & SB-50 & SB-70 & DB-50-50 & S-50 \\
\hline GGI & 0.3 & 0.30 & 0.30 & 0.29 & 0.30 \\
CGI & 0.9 & 0.87 & 0.84 & 0.84 & 0.90 \\
Se/GI & 2 & 1.87 & 2.18 & 1.90 & 1.88 \\
\hline
\end{tabular}

The EQE spectra of the three single selenized devices are shown in Fig. 6. The devices on the barrier layers have a higher collection compared to the barrier-free counterpart. The 'SB-70' device has the best collection, just above $80 \%$ between 540 and $570 \mathrm{~nm}$. This device also exhibited the highest $\mathrm{J}_{\mathrm{SC}}$ value of $24.3 \mathrm{~mA} / \mathrm{cm}^{2}$. A gradual decay of the QE is observed in longer wavelengths for all the devices. This is likely attributed to recombination losses in the fine-grained part of absorber layer. The small decay below $530 \mathrm{~nm}$ is due to the absorption in the CdS layer. The inset of Fig. 6 shows the extracted band gaps $\left(E_{\mathrm{g}}\right)$ from the EQE curves. The band gap is slightly lower for the longer selenization, which is likely due to variation of S/Se, given that the GGI is constant. The sulphur content was difficult to be quantified with EDX due to a peak overlap with Mo.

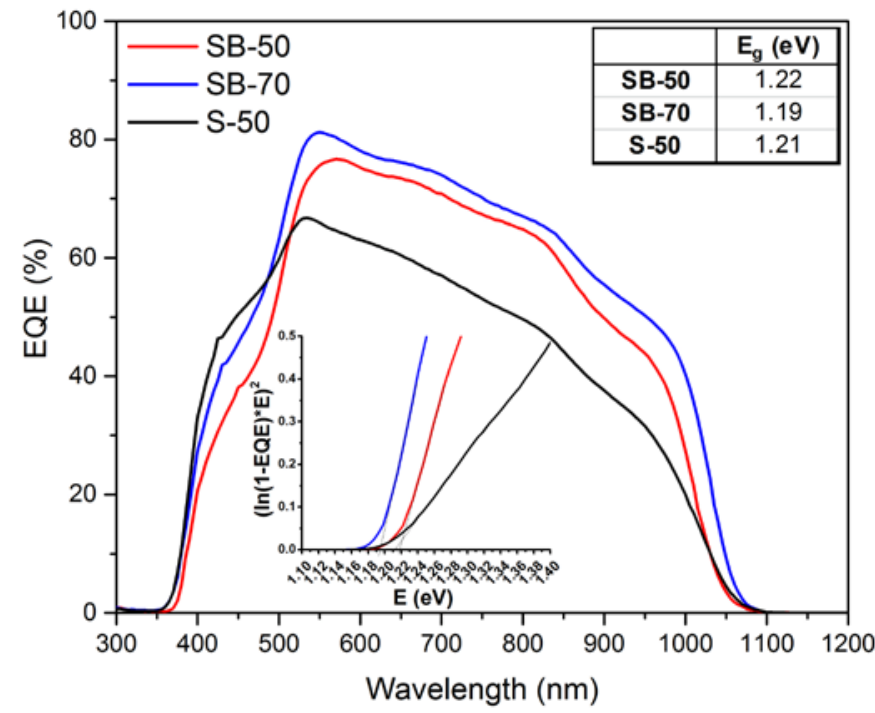

Fig. 6. EQE spectra of the CIGS solar cells. The inset shows the absorber band gap, as extracted from the EQE.
A method typically used to determine the dominating recombination path is JVT. The activation energy for recombination $\left(E_{A}\right)$ can be estimated from the JVT measurement. In the plot of the $\mathrm{V}_{\mathrm{OC}}$ vs. Temperature (Fig. 7), the linear extrapolation to $T=0 \mathrm{~K}$ gives the $\mathrm{E}_{\mathrm{A}}$ for each sample. Activation energy equal or close to the band gap indicates that the SRH recombination in the bulk is dominant. Values lower than the band gap indicate that the major recombination occurs at the heterojunction interface. For both devices (i.e. with and without $\mathrm{MoN}_{\mathrm{x}}$ barrier) the extracted $\mathrm{E}_{\mathrm{A}}$ is smaller than the band gap, suggesting that the main recombination path is interface recombination. As seen from the SEM images, larger grains cover the porous fine-grained bottom layer. However the crystallized absorber layer does not fully cover the surface and so the porous absorber may come in contact with the CdS buffer layer. This could be responsible for the junction recombination losses.

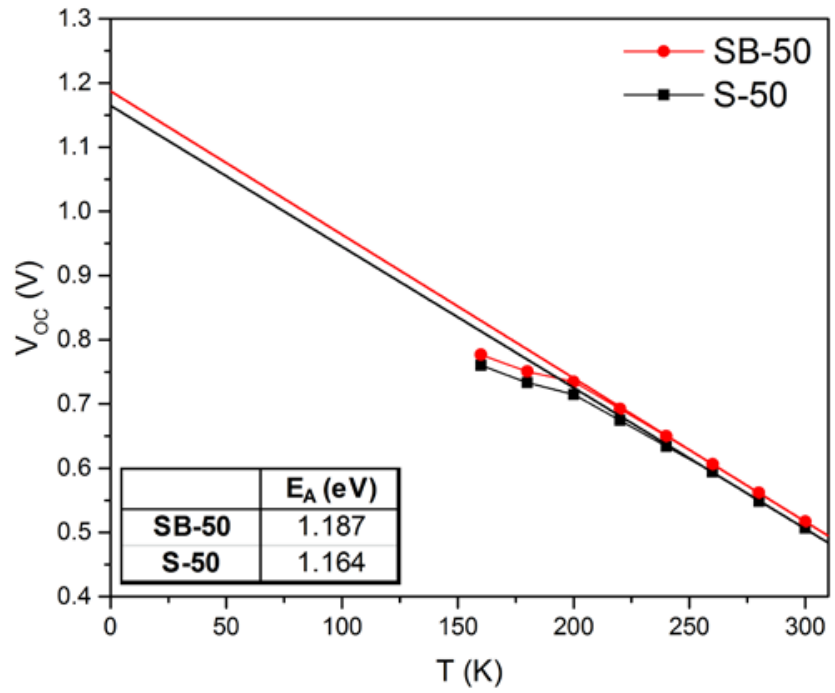

Fig. 7. $\mathrm{V}_{\mathrm{OC}}$ vs. Temperature obtained from the JVT measurement.

\section{CONCLUSIONS}

The $\mathrm{MoN}_{\mathrm{x}}$ barrier layer was effectively introduced at the back contact for hydrazine-free solution-processed CIGS solar cells. The barrier layer was shown to effectively block Se diffusion during selenization, hence controlling the $\mathrm{MoSe}_{2}$ formation. Excessive $\mathrm{MoSe}_{2}$ formation was shown to cause delamination problems. CIGS solar cells with the barrier layer reached comparable or even higher efficiencies to the baseline device on bare Mo. Moreover, the barrier layer allows for longer or multiple selenizations, resulting in better crystallization and consequently higher $\mathrm{J}_{\mathrm{SC}}$ and $\mathrm{V}_{\mathrm{OC}}$ values. FF was improved, especially for the double selenized device, where the fine-grain layer thickness was substantially reduced. The QE loss in the red portion of the spectrum for all the single selenized samples indicates that there is still room for improvement in terms of the absorber quality. Nonetheless, this work shows that the application of the barrier layer allows 
a broader process window for the selenization step. Further work is required to test whether the barrier hinders $\mathrm{Na}$ diffusion from the substrate or causes compositional variations.

\section{ACKNOWLEDGEMENTS}

The authors would like to thank Edgardo Saucedo and Sergio Giraldo, IREC, Spain for EQE measurements. The authors are also grateful for funding from the EPSRC (EP/N026438/1) to support this work.

\section{REFERENCES}

[1] P. Jackson, R. Wuerz, D. Hariskos, E. Lotter, W. Witte, and M. Powalla, "Effects of heavy alkali elements in $\mathrm{Cu}(\mathrm{In}, \mathrm{Ga}) \mathrm{Se} 2$ solar cells with efficiencies up to $22.6 \%$," Phys. status solidi Rapid Res. Lett., vol. 4, 2016.

[2] T. K. Todorov, O. Gunawan, T. Gokmen, and D. B. Mitzi, "Solution-processed $\mathrm{Cu}(\mathrm{In}, \mathrm{Ga})(\mathrm{S}, \mathrm{Se})_{2}$ absorber yielding a 15.2\% efficient solar cell," Prog. Photovoltaics Res. Appl., vol. 21, 2013.

[3] D. H. Webber and R. L. Brutchey, "Alkahest for V2VI3 chalcogenides: dissolution of nine bulk semiconductors in a diamine-dithiol solvent mixture.," J. Am. Chem. Soc., vol. 135, 2013.

[4] P. Arnou, C. S. Cooper, S. Uličná, A. Abbas, A. Eeles, L. D. Wright, A. V. Malkov, J. M. Walls, and J. W. Bowers, "Solution processing of $\mathrm{CuIn}(\mathrm{S}, \mathrm{Se})_{2}$ and $\mathrm{Cu}(\mathrm{In}, \mathrm{Ga})(\mathrm{S}, \mathrm{Se})_{2}$ thin film solar cells using metal chalcogenide precursors," Thin Solid Films, 2016.

[5] D. Zhao, Q. Tian, Z. Zhou, G. Wang, Y. Meng, D. Kou, W. Zhou, D. Pan and S. Wu, "Solution-deposited pure selenide CIGSe solar cells from elemental Cu, In, Ga, and Se,” J. Mater. Chem. A, 2015.

[6] X. Zhao, M. Lu, M. Koeper, and R. Agrawal, "SolutionProcessed Sulfur Depleted $\mathrm{Cu}(\mathrm{In}, \mathrm{Ga}) \mathrm{Se}_{2}$ Solar Cells
Synthesized from a Monoamine-Dithiol Solvent Mixture,” $J$. Mater. Chem. A, 2016.

[7] D. Abou-Ras, G. Kostorz, D. Bremaud, M. Kalin, F. V Kurdesau, A. N. Tiwari, and M. Dobeli, "Formation and characterisation of $\mathrm{MoSe}_{2}$ for $\mathrm{Cu}(\mathrm{In}, \mathrm{Ga}) \mathrm{Se}_{2}$ based solar cells," Thin Solid Films, vol. 480, 2005.

[8] X. L. Zhu, Z. Zhou, Y. M. Wang, L. Zhang, a M. Li, and F. Q. Huang, "Determining factor of $\mathrm{MoSe}_{2}$ formation in $\mathrm{Cu}(\mathrm{In}, \mathrm{Ga}) \mathrm{Se}_{2}$ solar Cells,” Sol. Energy Mater. Sol. Cells, vol. 101, 2012.

[9] T. Schnabel and E. Ahlswede, "On the interface between kesterite absorber and Mo back contact and its impact on solution-processed thin-film solar cells," Sol. Energy Mater. Sol. Cells, vol. 159, 2017.

[10] A. Duchatelet, G. Savidand, R. N. Vannier, and D. Lincot, "Optimization of $\mathrm{MoSe}_{2}$ formation for $\mathrm{Cu}(\mathrm{In}, \mathrm{Ga}) \mathrm{Se}_{2}$-based solar cells by using thin superficial molybdenum oxide barrier layers,” Thin Solid Films, vol. 545, 2013.

[11] C. W. Jeon, T. Cheon, H. Kim, M. S. Kwon, and S. H. Kim, "Controlled formation of $\mathrm{MoSe}_{2}$ by $\mathrm{MoN}_{\mathrm{x}}$ thin film as a diffusion barrier against Se during selenization annealing for CIGS solar cell,” J. Alloys Compd., vol. 644, 2015.

[12] J. H. Scofield, a. Duda, D. Albin, B. L. Ballard, and P. K. Predecki, "Sputtered molybdenum bilayer back contact for copper indium diselenide-based polycrystalline thin-film solar cells,” Thin Solid Films, vol. 26, 1995.

[13] D. Zhao, Q. Fan, Q. Tian, Z. Zhou, Y. Meng, D. Kou, W. Zhou, S. Wu, J. Mater, D. Zhao, A. Qingmiao Fan, A. Qingwen Tian, A. Zhengji Zhou, A. Yuena Meng, A. Dongxing Kou, A. Wenhui Zhou, and S. Wu, "Eliminating Fine-Grained Layer in $\mathrm{Cu}(\mathrm{In}, \mathrm{Ga})(\mathrm{S}, \mathrm{Se})_{2}$ Thin Films for Solution-Processed High Efficient Solar Cells,” J. Mater. Chem. A, 2013.

[14] J. F. Guillemoles, L. Kronik, D. Cahen, U. Rau, A. Jasenek, and H.-W. Schock, "Stability Issues of $\mathrm{Cu}(\mathrm{In}, \mathrm{Ga}) \mathrm{Se}_{2}$-Based Solar Cells,” J. Phys. Chem. B, vol. 104, 2000.

[15] J. T. Heath, J. D. Cohen, and W. N. Shafarman, "Bulk and metastable defects in $\mathrm{CuIn}_{1-\mathrm{x}} \mathrm{Ga}_{\mathrm{x}} \mathrm{Se}_{2}$ thin films using drive-level capacitance profiling," J. Appl. Phys., vol. 95, 2004. 